\title{
Jessner's Lymphocytic Infiltrate - A Rare Case Report
}

\author{
Preeti Mishra ${ }^{1}$, Sunita Vagha ${ }^{2}$, Keshav Hiwale ${ }^{3}$, Samarth Shukla ${ }^{4}$ \\ 1, 2,3,4 Department of Pathology, Jawaharlal Nehru Medical College, DMIMSU, \\ Sawangi, Wardha, Maharashtra, India.
}

\section{INTRODUCTION}

Immune system acts as a protective barrier from harmful factors. The key element of immune system is lymphocyte. It plays important role in the pathogenesis of various disorders. One of them is a skin disorder called as Jessner's lymphocytic infiltrate which is characterized by lymphocytic infiltration in skin. It is a rare skin disorder the cause of which is unknown. This was first described by Jessner and Kanof in 1953. It is a benign chronic $\mathrm{T}$ cell infiltrative disorder where patient presents with erythematous plaques, are present in face, neck, upper trunk and back. The disease affects middle aged male and female and rarely affects children. The other names of Jessner's lymphocytic infiltrate are benign lymphocytic infiltrate, Jessner's Kanof lymphocytic infiltrate, and benign chronic $\mathrm{T}$ cell infiltrative disease. The differential diagnosis are discoid lupus erythematosus, leprosy, polymorphous light eruption, lymphocytoma cutis, and lymphoma. Treatment with anti-malarial (Hydroxychloroquine) is usually effective in case with photosensitivity. We present a case of 28 year male with the chief complaints of erythematous lesion over upper lip since 01 month. Diagnostic skin biopsy with Haematoxylin and Eosin stain and direct immunofluorescence leads the diagnosis of Jessner's lymphocytic infiltration of skin.

Jessner's lymphocytic infiltration is a rare disorder with unknown aetiology, although it has genetic or hereditary component. The disease has the same course as that of autoimmune disease. Patient presents with solid red coloured erythematous plaque or nodule on face, trunk, neck and back. Plaques are present in sun exposed areas; the usual age of presentation is $3^{\text {rd }}$ to $5^{\text {th }}$ decade with slight female preponderance ${ }^{1}$ Several studies have been done and found that this disorder is a subtype of lupus erythematosus.

\section{PRESENTATION OF CASE}

A 28-year-old male presented with the chief complaints of lesion over upper lip since one month. Patient also had a history of itching and redness. On cutaneous examination, well defined erythematous patch over upper lip was present with loss of hair at the patch present. Primary diagnosis of the lesion was discoid lupus erythematous, leprosy, polymorphous light eruption, lymphocytoma cutis, and lymphoma. The complete blood count was under normal range. Renal function test, kidney function test and thyroid function test were also normal. Lastly, skin biopsy was done, and the biopsy specimen was sent to histopathology. On gross examination, single, irregular whitish brown tissue piece measuring less than $0.5 \times 0.5 \mathrm{~cm}$ with skin attached. Haematoxylin and eosin staining was done. Microscopic examination reveals normal epidermis, dermis shows moderately dense perivascular and diffuse infiltrates of mature lymphocytes mixed with occasional histiocytes and plasma cells (Photomicrograph 1, 2). To rule out leprosy and discoid lupus erythematous, Fite Farraco stain was done which turned out to be negative and direct immunofluorescence was negative respectively.
Corresponding Author: Dr. Preeti Mishra, Department of Pathology, Jawaharlal Nehru Medical College, DMIMSU, Sawangi, Wardha, Maharashtra, India.

E-mail: preeti1707mishra@gmail.com

\section{DOI: $10.14260 / j e m d s / 2020 / 854$}

How to Cite This Article:

Mishra P, Vagha S, Hiwale K, et al. Jessner's lymphocytic infiltrate: a rare case report. J Evolution Med Dent Sci 2020;9(51):38983899, DOI: $10.14260 /$ jemds/2020/854

Submission 23-08-2020,

Peer Review 18-10-2020,

Acceptance 26-10-2020,

Published 21-12-2020.

Copyright (c) 2020 Preeti Mishra et al. This is an open access article distributed under Creative Commons Attribution License [Attribution 4.0 International (CC BY 4.0)] 


\section{DISCUSSION}

In 1953, Jessner and Kanof identified a skin condition popularly called as Jessner's lymphocytic infiltrate which is a rare skin condition characterized by benign chronic $\mathrm{T}$ cell infiltration. It is classified under benign $\mathrm{T}$ cell lymphoproliferative disorder. Some cases of Jessner's lymphocytic infiltrate are associated with Borrelia Infection (Lyme Disease). ${ }^{1,2}$

JLI (Jessner's Lymphocytic Infiltrate) classically presents as red tumid nodule / plaque over face, neck, upper trunk, and back with slight seasonal variation. It gets precipitated during winters. The lesions are smooth, raised non scaling erythematous nodules or plaques. Lesions usually disappear but can recur at the previous site or anywhere in the body. Some other diseases having similar patchy dermal infiltration are discoid lupus erythematosus, leprosy, polymorphous light eruption, mycosis fungoides, granuloma annulare, lymphocytoma cutis, and lymphoma must be ruled out to reach a final diagnosis. ${ }^{3}$ Jessner's lymphocytic infiltrate occurs in sun exposed area whereas DLE (Discoid Lupus Erythematosus) may or may not occur in sun exposed area, hyperkeratosis is absent in Jessner's lymphocytic infiltrate whereas it is present in DLE, DIF (Direct ImmunoFluorescence) plays a significant role in making a final diagnosis which is positive in DLE and negative in JLI. Other differentials include mycosis fungoides, which is one of the common types of cutaneous $\mathrm{T}$ cell lymphoma also called as mature $\mathrm{T}$ cell non-Hodgkin's lymphoma caused by proliferation of small to medium sized lymphocytes with cerebriform nuclei. Histological examination reveals diffuse lymphocytic infiltrate in papillary dermis with a tendency of lymphoid cells to line up close to epidermis. Epidermotropism is an important clue for the diagnosis of mycosis fungoides. Sezary syndrome is erythrodermic cutaneous $\mathrm{T}$ cell lymphoma, which presents as classical triad of erythroderma, peripheral lymphadenopathy, and atypical mononuclear cells. CBC (Complete Blood Count) shows raised total leucocyte count and presence of Sezary's cells on buffy coat preparations. Histopathologic examination reveals absence of epidermotropism with the presence of mixed dermal infiltrate composed of atypical lymphocytes with large nuclei. Lymphocytoma cutis is also known as cutaneous lymphoid hyperplasia is lymphoproliferative response to variety of stimuli that results in accumulation of lymphocytes and other inflammatory cells. It is B cell pseudolymphoma. Histologically, nodular aggregates of B cells with germinal centres containing prominent tangible body macrophages. ${ }^{1,3,4}$

Some studies have been done on Jessner's lymphocytic infiltrate by Willimze et al, Vanhale et al, Winkelman et al, Cerio et al, Dippel et al and they found that it is predominantly $\mathrm{T}$ cell infiltrative disorder composed of mixture of $\mathrm{T}$ helper cell and $\mathrm{T}$ suppressor cell and there is also evidence of foci of perivascular B lymphocyte surrounded by T lymphocytes. ${ }^{5}$

Treatment remains unsatisfied but some drugs like topical and intralesional corticosteroids, antimalarials, thalidomide and tetracyclines and PUVA (psoralen and ultraviolet A) therapy are found effective against this. Treatment with hydroxychloroquine is found effective for the treatment of Jessner's lymphocytic infiltrate. 6,7
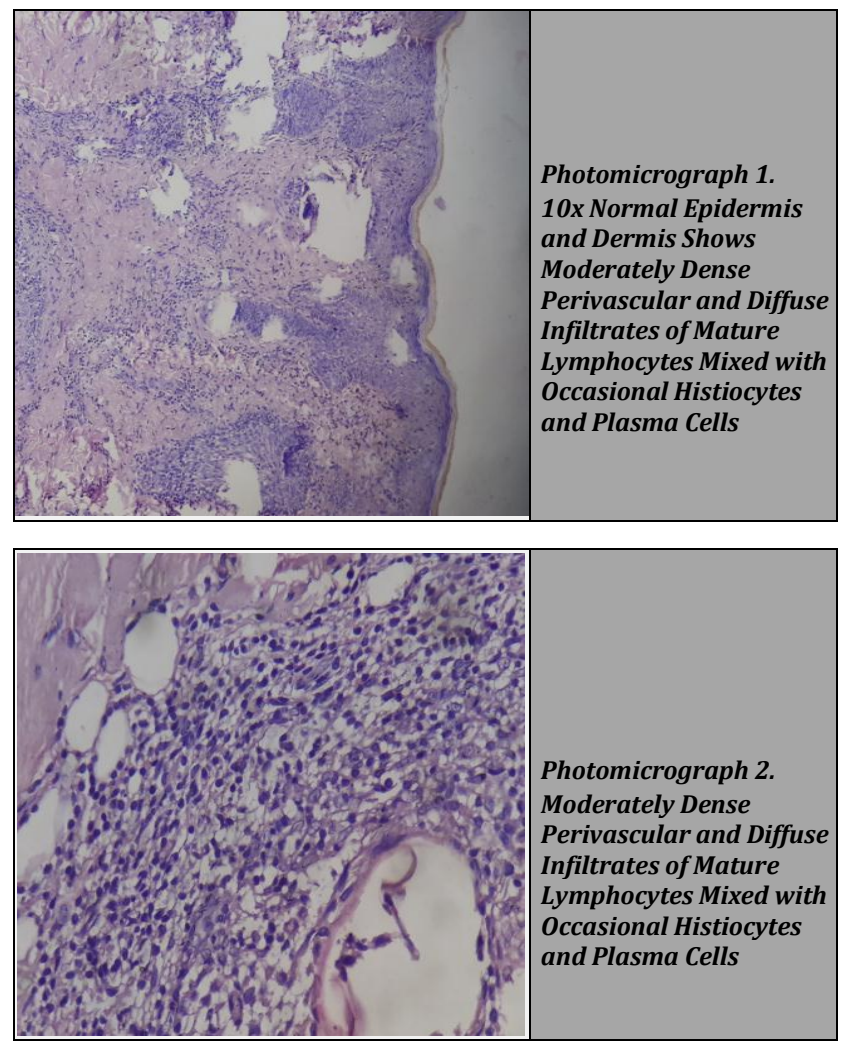

\section{CONCLUSIONS}

It is a benign chronic disorder. Its clinical course is cyclic with remissions and exacerbations. This disorder is not associated with increased mortality. However, the prognosis is good.

Financial or other competing interests: None.

Disclosure forms provided by the authors are available with the full text of this article at jemds.com.

\section{REFERENCES}

[1] Dhaou B, Dahmen F, Amor A, et al. Jessner's lymphocytic infiltration of the skin: a new case. Journal of the Saudi Society of Dermatology \& Dermatologic Surgery 2012;16(2):77-9.

[2] Jessner M, Kanof B. Lymphocytic infiltration of the skin. Arch Dermatol 1953;68:447-9.

[3] Prasad PG, Rama R, Laksmi SJ, et al. Benign lymphocytic infiltration of skin: a case report. Journal of Evolution of Medical and Dental Sciences 2015;4(28):4904-8.

[4] Toonstra J, Wildschut A, Boer J, et al. Jessner's lymphocytic infiltration of the skin. A clinical study of 100 patients. Arch Dermatol 1989;125(11):1525-30.

[5] Winhoven S, Coulson I. 50 Years of Jessner's lymphocytic infiltrate- a rare dermatosis revisited. Journal of the American Academy of Dermatology 2004;50(3):P52.

[6] Gottlieb B, Winkelmann RK. Lymphocytic infiltration of skin. Arch Dermatol 1962;86(5):626-33.

[7] Lipsker D, Mitschler A, Grosshans E, et al. Could Jessner's lymphocytic infiltrate of the skin be a dermal variant of lupus erythematosus? An analysis of 210 cases. Dermatology 2006;213(1):15-22. 